\title{
Antenatal breast milk expression at term increases postnatal lactational performance
}

\author{
P. A. Uikey, Palak Agrawal*, Surekha Khandale
}

Department of Obstetrics and Gynecology, IGGMCH, Nagpur, Maharashtra, India

Received: 02 March 2017

Revised: 05 May 2017

Accepted: 10 May 2017

\author{
*Correspondence: \\ Dr. Palak Agrawal, \\ E-mail: palak1412@gmail.com
}

Copyright: (c) the author(s), publisher and licensee Medip Academy. This is an open-access article distributed under the terms of the Creative Commons Attribution Non-Commercial License, which permits unrestricted non-commercial use, distribution, and reproduction in any medium, provided the original work is properly cited.

\begin{abstract}
Background: Breast milk contains balanced nutrients for the complete growth of body and brain of neonates and infants. Breast feeding is rich in anti-infective factors and improves immune system, thus reducing the child mortality rate. Objective of present work was to study the effect of antenatal breast milk expression at term in improving lactational performance as compared to control group.

Methods: The prospective, comparative study was conducted for 2 years to observe effects of antenatal expression of breast milk on postnatal lactational performance in a tertiary care centre in Central India. 200 Subjects after 37 weeks of pregnancy divided in two groups of 100 each 1) study group 2) control group by systematic random sampling technique. Prior examination was done to exclude any inverted or cracked nipples and appropriate treatment instituted. The women with diseased breast and conditions, high risk pregnancy, congenitally anomalous fetus and drugs affecting lactation were excluded from study. Study group women were counselled to express milk 2-3 times every day preferably during bathing. All women were followed up in hospital and postnatal lactation performance was observed in both groups.

Results: The study group did not find it difficult to initiate breast feeding after vaginal or caesarean delivery and in $78 \%$ of patients time interval from initiation of lactation to establishment of lactation was less than half hour as compared to control group $(38 \%) \mathrm{P}$ value $<0.001$. Statistical analysis showed significant difference in the results of those groups.
\end{abstract}

Conclusions: Daily antenatal breast milk expression after 37 weeks of pregnancy significantly reduced the time for establishing full breast feeding and reduced breast feeding failures.

Keywords: Antenatal breast milk expression, Lactational performance, Interval from initiation to lactation

\section{INTRODUCTION}

Breast milk contains balanced nutrients for the complete growth of body and brain of neonates and infants. Breast feeding is rich in anti-infective factors and improves immune system, thus reducing the child mortality rate. ${ }^{1}$

Breast feeding also offers several benefits to the mother by improving post-partum recovery, partial birth control, and reduced risk of ovarian and breast cancers. ${ }^{2}$ For these reasons, breast feeding for the first 6 months of life and continuing at least until 12 months of life continues to be strongly recommended. If such a recommendation is to be successfully implemented, breast feeding should be encouraged and supported prenatally, perinatally and postnatally. Obstacles to the establishment of breast feeding include inadequate prenatal education and promotion, lack of support, cultural views, promotion of 
commercial formulae, hospital practices, and lack of follow up after discharge from the hospital. ${ }^{3}$

The motivation and preparation of breast feeding should start during antenatal period. Willingness, keenness and confidence in the mother are crucial for successful establishment of breastfeeding. Early breastfeeding in all babies, irrespective of the mode of delivery, and avoidance of prelacteal and prolacteal feeds are essential to establish successful breast feeding. ${ }^{3}$

During the first 2-3 days of delivery, when lactation is not fully established, the mother is often anxious, that her baby is not getting adequate nourishment. So, they give top feeding to the baby. Normal healthy newborns do not require any type of prelacteal feeds as colostrum is sufficient to meet the needs of the newborn baby. The administration of prelacteal feeds interferes with sucking and prolactin production, and ultimately undermines confidence in the mother's ability to breastfeed. ${ }^{3}$

Top feeding has disadvantages that the formula feeds available are expensive and lack of antibodies, requires adequete hygiene not adequately met in the undereducated and poor socioeconomic class and rural areas of Indian society. As a result, the neonatal morbidity increases significantly due to the ensuing neonatal infections. And also, it is true that no formula can exactly duplicate the ideal composition of breastmilk.

Thus, in order to obviate this initial period of 2-3 days when supplementary feed may be required for the newborn, gentle emptying of breasts daily after 37 completed weeks of gestation can be advised. Present study aims at observing the effects of antenatal expression of breastmilk at term on lactational performance.

Aims and objective of present work was to study the effect of antenatal breast milk expression in improving postnatal lactational performance as compared to conventional method for establishment of breastfeeding, to counsel mother's importance of early breast feeding and compare its benefits for both the mother and child and to educate mothers about exclusive breast feeding and avoidance of prelacteal and postlacteal feeds.

\section{METHODS}

The prospective, comparative study was conducted for 2 years to observe effects of antenatal expression of breast milk on postnatal lactational performance in a tertiary care centre in Central India. 200 Subjects were divided in two groups of 100 each one is study group and second is control group by systematic random sampling technique. Subjects were enrolled after obtaining written informed consent for participation in the study and selected by predefined inclusion and exclusion criteria. The study was approved by the ethics committee of the institution.

\section{Inclusion criteria}

- All pregnant women with certain dates aged between 20-35 years after 37 completed weeks of gestation.

- All booked antenatal cases who are receptive to knowledge about breastfeeding and willing to participate and for follow-up.

\section{Exclusion criteria}

- Women with diseased breast condition like sore nipples or cracked nipples or retracted nipples

- Women with conditions those affect the breastfeeding rates like hypothyroidism and hypoprolactinemia

- Women with other habits (smoking, alcohol), and on drugs like anticonvulsant, antidepressant and antithyroid.

- Patients with high risk pregnancies such as multiple gestation or diabetes or preeclampsia or anemia or fetal conditions like IUGR or oligohydramnios

- Patients with current pregnancy with congenitally anomalous baby

Study Group 1 was counselled regarding the technique of antenatal breast milk expression as described below and were advised to do so on their own at home 2-3 times daily till delivery. Control group 2 was not advised to do so. Both groups delivered in our institute Patients were encouraged to have skin to skin contact and to breastfeed the child within half an hour following vaginal delivery and within 2-3 hours following caesarean section. ${ }^{4}$ After delivery subjects were followed in both the groups till complete establishment of lactation.

During this period subjects were examined thrice daily and enquired about the initiation and establishment of breast feeding. The time required for the first breast feed after delivery was considered as time for initiation of breast feeding. The feeding experience was measured as per the neonatal satisfaction. Neonatal satisfaction means breast feeding given on demand and adequate sleep for about 2 hours after each feed. ${ }^{4}$ Neonatal satisfaction indicated complete establishment of lactation. The time interval required from initiation of breast feeding to complete establishment of breast feeding was noted in both the groups and compared using appropriate statistical tests.

- Always wash hands before expressing.

- Apply a warm compress to breast or express after a warm bath or shower. It helps the flow of colostrum.

- After getting in a comfortable position patient is advised to start with a gentle breast massage, stroking from the back of breast towards the nipple to facilitate the let-down reflex.

- Put thumb above the nipple and first few fingers below the nipple. There will be cupping the breast in a 'C' shape. 
- Move thumb and fingers a few centimetres back from the nipple. Press in towards chest, press fingers together and draw them forwards. Repeat this process, building up a rhythm.

- Colostrum should start to arrive drop by drop. Initially it may just be a glisten on the end of nipple and it may take a few days of practise before drops appear.

\section{RESULTS}

Out of 100 patients in study group $78(78 \%)$ established full lactation within half an hour of initiation of lactation of breast feeding, whereas in the control group only 38 $(38 \%)$ had established lactation within half an hour. The difference was statistically significant $(\mathrm{P}<0.001)$.

Table 1: Distribution of study and control group as per time interval between initiation and establishment of lactation.

\begin{tabular}{|c|c|c|c|c|}
\hline $\begin{array}{l}\text { Time interval between initiation and } \\
\text { establishment of lactation }\end{array}$ & $\begin{array}{l}\text { Study group } \\
(\mathrm{n}=\mathbf{1 0 0})\end{array}$ & $\begin{array}{l}\text { Control group } \\
(\mathbf{n}=\mathbf{1 0 0})\end{array}$ & $\begin{array}{l}\text { Chi square } \\
\text { value }\end{array}$ & P value \\
\hline Less than $1 / 2$ hour & $78(78 \%)$ & $38(38 \%)$ & \multirow{4}{*}{32.85} & \multirow{4}{*}{$\begin{array}{l}<0.001 \\
\text { Significant }\end{array}$} \\
\hline $1 / 2$ to 72 hours & $18(18 \%)$ & $50(50 \%)$ & & \\
\hline More than 72 hours & $4(4 \%)$ & $12(12 \%)$ & & \\
\hline Total & $100(100 \%)$ & $100(100 \%)$ & & \\
\hline
\end{tabular}

Table 2: Mode of delivery and lactation.

\begin{tabular}{|c|c|c|c|c|c|c|c|c|}
\hline & Study group & & & & Control Gr & up & & \\
\hline $\begin{array}{l}\text { Time interval } \\
\text { between } \\
\text { initiation and } \\
\text { establishment } \\
\text { of lactation }\end{array}$ & $\begin{array}{l}\text { Vaginal } \\
\text { deliveries } \\
(n=78)\end{array}$ & $\begin{array}{l}\text { LSCS } \\
(n=22)\end{array}$ & $\begin{array}{l}\text { Chi } \\
\text { square }\end{array}$ & $\begin{array}{l}P \\
\text { value }\end{array}$ & $\begin{array}{l}\text { Vaginal } \\
\text { delivery }\end{array}$ & $\begin{array}{l}\text { Caesarian } \\
\text { delivery }\end{array}$ & $\begin{array}{l}\text { Chi } \\
\text { square }\end{array}$ & P Value \\
\hline $\begin{array}{l}\text { Less than 1/2 } \\
\text { hour }\end{array}$ & $71(91.02 \%)$ & $7(31.81 \%)$ & \multirow{4}{*}{40.37} & \multirow{4}{*}{$\begin{array}{l}<0.001 \\
\text { Significant }\end{array}$} & $32(40 \%)$ & $6(30 \%)$ & \multirow{4}{*}{1.004} & \multirow{4}{*}{$\begin{array}{l}0.6052 \\
\text { Not } \\
\text { significant }\end{array}$} \\
\hline $1 / 2$ to 72 hours & $4(5.13 \%)$ & $14(63.63 \%)$ & & & $38(47.5 \%)$ & $12(60 \%)$ & & \\
\hline $\begin{array}{l}\text { More than } 72 \\
\text { hours }\end{array}$ & $3(3.84 \%)$ & $1(4.54 \%)$ & & & $10(12.5 \%)$ & $2(10 \%)$ & & \\
\hline Total & $78(100 \%)$ & $22(100 \%)$ & & & $80(100 \%)$ & $20(100 \%)$ & & \\
\hline
\end{tabular}

Table 2 shows time interval from initiation of lactation to full lactation in vaginal and caesarean deliveries. Significantly more women established full lactation within half an hour after vaginal delivery than after caesarean delivery in study group. $\mathrm{P}<0.001$ in the study group $\mathrm{P}$ value 0.6052 in control group.

Table 3: Time interval from initiation of lactation to full lactation in study group and control group in vaginal deliveries.

\begin{tabular}{|c|c|c|c|c|}
\hline $\begin{array}{l}\text { Time interval between initiation and establishment of } \\
\text { lactation }\end{array}$ & $\begin{array}{l}\text { Study group } \\
(\mathrm{n}=78)\end{array}$ & $\begin{array}{l}\text { Control group } \\
(\mathrm{n}=\mathbf{8 0})\end{array}$ & $\begin{array}{l}\text { Chi square } \\
\text { value }\end{array}$ & $\begin{array}{l}\mathbf{P} \\
\text { value }\end{array}$ \\
\hline Less than $1 / 2$ hour & $71(91 \%)$ & $32(40.0 \%)$ & \multirow{4}{*}{46.04} & \multirow{4}{*}{$<0.001$} \\
\hline $1 / 2$ hr to 72 hours & $4(5.1 \%)$ & $38(47.5 \%)$ & & \\
\hline More than 72 hours & $3(3.8 \%)$ & $10(12.5 \%)$ & & \\
\hline Total & $78(100 \%)$ & $80(100 \%)$ & & \\
\hline
\end{tabular}

Table 3 shows time interval from initiation of lactation to full lactation in study group and control group in vaginal deliveries. The results for above were analyzed statistically with chi square test and significant difference was found between two sub group at the $\mathrm{P}$ value of $\leq 0.001$. Table 4 shows time interval from initiation of lactation to full lactation in study group and control group in vaginal primiparas. The results for above were 
analyzed statistically with chi square test and significant difference was found between two sub group at the value of $\leq 0.001$. Table 5 shows time interval from initiation of lactation to full lactation in study group and control group in vaginal multiparas. The results for above were analyzed statistically with chi square test and significant difference was found between two sub group at the value of 0.002 .

Table 4: Distribution of primipara with no history of lactational experience as per time interval between initiation and establishment of lactation.

\begin{tabular}{|c|c|c|c|c|}
\hline $\begin{array}{l}\text { primipara with no history of lactational } \\
\text { experience }\end{array}$ & Study group & Control group & $\begin{array}{l}\text { Chi square } \\
\text { value }\end{array}$ & P value \\
\hline Less than $1 / 2$ hour & $52(75.36 \%)$ & $21(34.42 \%)$ & \multirow{4}{*}{20.47} & \multirow{4}{*}{$\begin{array}{l}<0.001 \\
\text { Significant }\end{array}$} \\
\hline $1 / 2$ to 72 hours & $16(23.19 \%)$ & $32(52.45 \%)$ & & \\
\hline More than 72 hours & $1(1.44 \%)$ & $8(13.11 \%)$ & & \\
\hline Total & $69(100 \%)$ & $61(100 \%)$ & & \\
\hline
\end{tabular}

Table 5: Distribution of multipara with previous history of lactational experience as per interval between initiation and establishment of lactation.

\begin{tabular}{|c|c|c|c|c|}
\hline $\begin{array}{l}\text { Multipara with previous history of } \\
\text { lactational experience }\end{array}$ & Study group & Control group & $\begin{array}{l}\text { Chi square } \\
\text { value }\end{array}$ & P value \\
\hline Less than $1 / 2$ hour & $26(83.87 \%)$ & $17(43.58 \%)$ & \multirow{4}{*}{12.21} & \multirow{4}{*}{$\begin{array}{l}0.002 \\
\text { Significant }\end{array}$} \\
\hline $1 / 2$ to 72 hours & $2(6.45 \%)$ & $18(46.15 \%)$ & & \\
\hline More than 72 hours & $3(9.67 \%)$ & $4(10.25 \%)$ & & \\
\hline Total & $31(100 \%)$ & $39(100 \%)$ & & \\
\hline
\end{tabular}

\section{DISCUSSION}

Breastfeeding is an inevitable part of an infant's life. It has been assigned supreme importance in obstetrics since ages.

Current evidence mostly from high income countries suggests that occurrence of non-communicable diseases may be programmed by exposures occurring during gestation or in the first few years of life. Early diets including the type of milk received, is one of the key exposures that may influence the development of adult diseases.

Breast milk is the normal food for infants. There are risks associated with the use of formula feeds and cow feeds like it may increase the incidence of juvenile onset diabetes. ${ }^{5,6}$ The neonatal bowel is immature especially in preterm infants, cross the bowel wall leading to increased incidences of neonatal morbidity. ${ }^{7}$ At a time when the newborn gut is vulnerable to pathogens and at risk of mucosal damage. Colostrum has high levels of lactose which is readily available to the infant after breakdown into glucose and galactose. ${ }^{8}$ Colostrum has high levels of immunosuppressive factors that reduce pro-inflammatory processes and inhibit specific pathogens. $^{7}$ Unlike formula, breast milk also accelerates maturation of the gut barrier function. ${ }^{?}$

In the past, women were encouraged to express colostrum antenatally; e.g. in 1972, Llewellyn-Jones recommended daily expressing from the $32^{\text {nd }}$ weeks to keep the ducts open. But preterm labour was thought to be a consequence to it, so antenatal expression of breast milk at term was considered.

Antenatal breast milk expression at term is an inexpensive and safe method to boost up the confidence in breastfeeding and to increase the availability of milk to the new born. Hence this study was conducted at a tertiary care hospital in central India with a view to observe effects of antenatal and top feed substances contain macromolecules which can expression of breast milk at term in healthy pregnant females on their postnatal lactational performance.

Table 1 shows distribution of time interval between initiation of lactation and establishment of lactation in study and control group.

Among all subjects, 78 (78\%) of the study group and 38 $(38 \%)$ of the control group had interval between initiation and establishment of lactation of less than $1 / 2$ hour while $18(18 \%)$ of the study group and $50(50 \%)$ of the control group had this interval between $1 / 2$ to 72 hours and $4(4 \%)$ of the study group and $12(12 \%)$ of the control group had this interval of more than 72 hours. $p$ value of this table is $<0.001$ which is significant which means that in this study the time interval between initiation and establishment of lactation is significantly less in study group as compared to control group. 
In study conducted by Lt Col Singh G et al 85 (94.44\%) of the study group and $63(70 \%)$ of the control group had interval of less than $1 / 2$ hour while $5(5.56 \%)$ of the study group and $25(27.78 \%)$ of the control group had interval between $1 / 2$ to 72 hours while $2(2.22 \%)$ of the control group had interval of more than 72 hours. ${ }^{9} \mathrm{p}$ value of this table was $<0.001$ which is significant.

In study conducted by Singh G et al $48(96 \%)$ of the study group and $36(72 \%)$ of the control group had interval between initiation and establishment of lactation of less than $1 / 2$ hour while $2(4 \%)$ of the study group and $13(26 \%)$ of the control group had this interval between $1 / 2$ to 72 hours and none from the study and only $1(2 \%)$ of the control group had this interval of more than 72 hours. $^{3}$ $\mathrm{p}$ value is $<0.001$ which is significant.

In study conducted by Lamba $\mathrm{S}$ et al the study group 89 $(89 \%)$ of the cases established full lactation within $6 \mathrm{~h}$ of delivery, whereas in the control group $72(72 \%)$ of the cases had established full lactation within $6 \mathrm{~h}^{10}$ The difference in both the groups was statistically significant $(\mathrm{P}<0.05)$ with regard to time interval from initiation of lactation to full lactation. Findings of these studies are comparable to present study which is suggestive of time interval between initiation of lactation to establishment of lactation in study group being significantly less than control group.

Table 2 shows time interval between initiation of lactation and establishment of lactation in study group and control group in vaginal deliveries and LSCS.

Amongst 100 study group subjects, 78 had vaginal deliveries. Out of them $71(91.02 \%)$ had time interval between initiation and establishment of lactation of less than $1 / 2$ hour and $4(5.13 \%)$ had time interval between $1 / 2$ to 72 hours and $3(3.84 \%)$ had interval of more than 72 hours. Remaining 22 study group subjects had LSCS. Out of them $7(31.81 \%)$ had time interval between initiation and establishment of lactation of less than $1 / 2$ hour and 14 $(63.63 \%)$ had interval between $1 / 2$ to 72 hours and 1 $(4.54 \%)$ had interval of more than 72 hours. $p$ value of this table is $<0.001$ which is statistically significant.

In the study conducted by Lt Col Singh G et al amongst the study group subjects 72 had vaginal deliveries and 18 had LSCS. ${ }^{9} 72(100 \%)$ of the vaginal deliveries and 14 $(77.78 \%)$ of the LSCS patients had interval of less than $1 / 2$ hour. None of the vaginal deliveries and $4(22.22 \%)$ of the patients with LSCS had interval between $1 / 2$ to 72 hours. None of the patients in the study or control group had interval of more than 72 hours. $\mathrm{P}$ value is $<0.001$ which is statistically significant.

In the study conducted by Singh $\mathrm{G}$ et al the study group subjects 41 had vaginal deliveries and 9 had LSCS. $41(100 \%)$ of the vaginal deliveries and $7(77.7 \%)$ of the LSCS patients had interval of less than $1 / 2$ hour. ${ }^{3}$ No patient who delivered vaginally and $2(22.2 \%)$ of the patients with LSCS had interval between $1 / 2$ to 72 hours. None of the patients in both the groups had interval of more than 72 hours. $\mathrm{P}$ value is 0.01 which is statistically significant.

Thus, the findings of these studies are similar to present study and thus it is suggestive of time interval between initiation of lactation and full lactation in study group in vaginal deliveries is significantly less than LSCS deliveries

Amongst 100 control group subjects, 80 had vaginal deliveries. Out of them $32(40 \%)$ had interval between initiation and establishment of lactation of less than $1 / 2$ hour and $38(47.5 \%)$ had interval of $1 / 2$ to 72 hours and 10 $(12.5 \%)$ had interval of more than 72 hours. Remaining 20 control group subjects had LSCS. Amongst them 6 (30\%) had interval between initiation and establishment of lactation of less than $1 / 2$ hour while $12(60 \%)$ had interval between $1 / 2$ to 72 hours and $2(10 \%)$ had interval of more than 72 hours. $p$ value of this table is 0.605 which is statistically not significant which means that there was no significant difference in control group in interval between initiation and establishment of lactation.

In the study conducted by Lt Col Singh $\mathrm{G}$ et al amongst the control group subjects $56(78.87 \%)$ of the vaginal deliveries and $8(42.15 \%)$ of the LSCS patients had interval of less than $1 / 2$ hour. ${ }^{9} 13(18.31 \%)$ of the vaginal deliveries and $11(57.89 \%)$ of the patients with LSCS had interval between $1 / 2$ to 72 hours. $2(2.82 \%)$ of the patients with vaginal delivery had interval of more than 72 hours. $\mathrm{P}$ value is $<0.001$ which is statistically significant.

In the study conducted by Singh $\mathrm{G}$ in the control group $32(80 \%)$ of the vaginal deliveries and $4(40 \%)$ of the LSCS patients had interval of less than $1 / 2$ hour. ${ }^{3} 7$ $(17.5 \%)$ of the patients with vaginal delivery and $6(60 \%)$ with LSCS had interval between $1 / 2$ to 72 hours. $1(2.5 \%)$ of the patients with vaginal delivery and none with LSCS had interval of more than 72 hours. $p$ value is 0.025 which is statistically significant. The $\mathrm{p}$ value of our study was not comparable to the above-mentioned studies.

In this study amongst the group of vaginal deliveries 71 (91\%) from the study group and $32(40 \%)$ from the control group had interval of less than $1 / 2$ hour while 4 $(5.1 \%)$ of the study group and $38(47.5 \%)$ from the control group had interval of $1 / 2$ to 72 hours and only 3 $(3.8 \%)$ of the study group and $10(12.5 \%)$ from the control group. In the study conducted by Lt Col Singh G et al amongst the group of vaginal deliveries from the test group $72(100 \%)$ had interval of less than $1 / 2$ hour while $56(78.87 \%)$ from the control group had similar interval, none from the study and $13(18.31 \%)$ from the control group had interval of $1 / 2$ hour to 72 hours and none from the study and only $2(2.82 \%)$ of the control group had interval of more than 72 hours. ${ }^{6}$ p value is $<0.001$ which is statistically significant. 
In the study conducted by Singh $\mathrm{G}$ amongst the group of vaginal deliveries from the test group $41(100 \%)$ had interval of less than $1 / 2$ hour while $32(80 \%)$ from the control group had similar interval. ${ }^{3}$ None of the vaginal deliveries had interval of more than $1 / 2$ hour, $7(17.5 \%)$ from the control group had interval of $1 / 2$ hour to 72 hours and only $1(2.5 \%)$ of the control group had interval of more than 72 hours. $p$ value is $<0.025$ which is statistically significant. The results were comparable to the studies and thus time interval from initiation of lactation to full lactation in study group is significantly less than control group in vaginal deliveries.

Table 4 shows distribution of nullipara with no history of lactational experience as per time interval between initiation and establishment of lactation. Amongst primipara with no history of lactational experience 52 (75.36\%) were from study group while 21 (34.42\%) were from control group who had interval between initiation and establishment of lactation of less than $1 / 2$ hour, 16 $(23.19 \%)$ from the study group and $32(52.45 \%)$ from the control group had interval of $1 / 2$ to 72 hours and $1(1.44 \%)$ of the study group and $8(13.11 \%)$ from the control group had interval of more than 72 hours. $p$ value is 0.001 which is statistically significant which is suggestive of time interval between initiation and establishment in study group being significantly less than control group in nulliparous patients with no history of lactational experience.

Table 5 shows distribution of multipara with previous history of lactational experience as per interval between initiation and establishment of lactation. Amongst multipara with previous history of lactational experience $26(83.87 \%)$ were from study group while $17(43.58 \%)$ were from control group who had interval between initiation and establishment of lactation of less than $1 / 2$ hour, $2(6.45 \%)$ from the study group and $18(46.15 \%)$ from the control group had interval of $1 / 2$ to 72 hours and $3(9.67 \%)$ of the study group and $4(10.25 \%)$ from the control group had interval of more than 72 hours. $P$ value is 0.002 which is statistically significant and this is suggestive of time interval between initiation and establishment in study group being significantly less than control group in multiparous patients with history of lactational experience.

\section{CONCLUSION}

The findings of this study are significant with regards to interval between initiation and establishment of lactation being significantly lesser in study group than control group. Antenatal breast expression after 37 weeks helps establish breast feeding quickly and efficiently.

Funding: No funding sources

Conflict of interest: None declared

Ethical approval: The study was approved by the Institutional Ethics Committee

\section{REFERENCES}

1. Fewtrell MS, Morgan JB, Duggan C, Gunnlaugsson G, Hibberd PL, Lucas A et al. Optimal duration of exclusive breastfeeding: what is the evidence to support current recommendations. Am J Clin Nutr. 2007;85:635S-638S.

2. Rea MF. Benefits of breastfeeding and women's health. J Pediatr (Rio J). 2004;80(S suppl):142-6.

3. Singh G, Dasgupta E. Effect of antenatal expression of breast milk at term to improve lactational performance: a prospective study. J Obstet Gynaecol India. 2009;59(4):308-11.

4. Dutta DC. Textbook of Obstetrics: The Term Newborn Infant: Jaypee Brothers Medical Publishers; 2015. $8^{\text {th }}$ edition: 520-23.

5. Cattaneo A. The benefits of breastfeeding or the harm of formula feeding. J Paediatr Child Health. 2008;44:1-2.

6. Virtanen SM, Rasenen L, Aro A, Lindstrom J, Sippola H, Lounamaa $\mathrm{R}$ et al. Infant feeding in Finnish children $<7 \mathrm{Yr}$ of age with newly diagnosed IDDM. Diabetes. 1991;14(5):415-7.

7. Newburg DS, Walker WA. Protection of the neonate by the innate immune system of developing gut and of human milk. Pediatr Res. 2007;61:2-8.

8. Jensen CL, Voigt RG, Llorente AM, Peters SU, Prager TC, Zou YL. Effects of early maternal docosahexaenoic acid intake on neuropsychological status and visual acuity at five years of age of breastfed term infants. J Pediatr. 2010;157(6):900-5.

9. Singh G, Chouhan R, Sidhu K. Effect of Antenatal expression of breast milk at term in reducing breast feeding failures. Med $\mathbf{J}$ Armed Forces India. 2009;65(2):131-3.

10. Lamba S, Chopra S, Negi M. Effect of antenatal breast milk expression at term pregnancy to improve post-natal lactational performance. J Obstet Gynaecol India. February 2016;66(1):30-4.

Cite this article as: Uikey PA, Agrawal P, Khandale $\mathrm{S}$. Antenatal breast milk expression at term increases postnatal lactational performance. Int J Reprod Contracept Obstet Gynecol 2017;6:2438-43. 